\title{
El Periquillo Sarniento y la Histoire de Gil Blas de Santillane
}

Fiste un estrecho parentesco entre el Gil Blas de Lesage y el Periquillo Sarniento de Fernández de Lizardi, pero un parentesco en el cual no hay que insistir demasiado, pues tanto en la concepción como en su significado son grandes las diferencias entre las dos obras. Así como en Lesage en vano se buscarán rasgos españoles, en Lizardi no se podrán encontrar características francesas. Lesage tomó de la picaresca española los elementos que precisaba, y con ellos labró su obra - obra que tanto en el plan como en el habla, tanto en la psicología como en los caracteres es enteramente francesa. Sólo hay allí de español el tema. Lizardi, al inspirarse en la francesa -o sea en el tema español en forma gala- logró crear una obra ni española ni francesa, sino mexicana. Una obra de una nitidez, de una psicología indígenas inconfundibles. Parece que antes de llegar a México a través de Francia, el género español pasara por un proceso evolutivo, depurador que lo limpiase de todo elemento ajeno y lo llevara a un estado de plasticidad que facilitó en gran medida el propósito de Lizardi de darle alma mexicana.

Pero, ¿por qué insistir en el abolengo francés de Periquillo Sarniento, si no tiene más de galo que unos cuantos episodios, y algunas descripciones más o menos idénticas? Porque, aunque no cabe duda que Lizardi conociera la literatura española, fué la francesa la que más influyó en él, y es lógico suponer que la conociese mejor. Su obra entera abunda en citas y alusiones a autores franceses, sin que aparezcan casi los españoles.

Las similaridades entre Gil y Perico son más bien de incidente y descripción, que de trama o plan. En realidad, la obra de Lesage 
tiende a lo difuso, y hay tantas interpolaciones que muy a menudo se pierde la hebra de la trama o se rompe lá continuidad de la acción, y hasta se olvida el lector del héroe. Lizardi, aunque carga su obra de divagaciones morales, aniquiladoras a veces, nunca nos deja perder de vista al protagonista principal. En Lizardi, el desarrollo de la personalidad del héroe se lleva a cabo con más lentitud; el proceso de su regeneración es más completo y por eso más verídico.

Gil Blas es una crítica velada cuyo disfraz español no engaña a nadie. Crítica de un mundo perfilado en una sola dimensión: el mundo aristocrático. E1 "petit monde", cuando figura en la narración, suele ser desvirtuado y carecer de personalidad propia, de individualidad, pues su habla nunca se hace sentir. El de Lizardi es un mundo visto en conjunto por unos ojos escudriñadores, traviesos y mordaces. Su lienzo es de grandes dimensiones y abarca todos los aspectos de la vida. La clase baja se codea con la rica; la pobreza, malicia e ignorancia de aquélla se contrasta con lo desalmado, vacuo y cruel de ésta. Hay tipos nuevos indigenas; figuran ladrones, indios, escribanos, frailes, "payos", subdelegados, aristócratas, mercaderes, y hasta un chino. Toda etapa social está allí representada.

Mucho se criticó a Lizardi cuando apareció Periquillo Sarniento, por contribuir al mal lenguaje y por lo escabroso y el mal gusto de muchos de los episodios. Esto no lo pudo soportar Lizardi, y en su "Apología" el Periquillo Sarniento se defiende: “... se asquea mucho de la aventura de los jarritos de orines que vaciaron los presos en la cárcel sobre el triste Periquillo, y del 'robo que hizo a un cadáver' ... ¿ en qué clase colocaremos la recíproca vomitada que se dieron Don Quijote y Sancho cuando aquél se bebió el precioso licor de Fierabrás? ¿Y cómo se llamará la limpísima diligencia que hizo Sancho de zurrarse junto a su amo por el miedo que le infundieron los batanes?" 1

A los que le atacaban por lo abundante y cargado de la moraleja, Lizardi contesta: "Don Quijote también moralizaba y predicaba a cada paso, y tanto que su criado le decía que podía coger un púlpito en las manos y andar por esos mundos predicando lindezas." ${ }^{2}$ Otros había que se quejaban de que sólo pintaba a la clase baja y ruin, y que debido a esto ya la gente iba perdiendo la ver- 
güenza y el uso del buen lenguaje. A éstos también contestó Lizardi: “... Nadie ha motejado que Cervantes introdujera a su héroe tratando con mesoneros y rameras, con cabreros y perillanes, burlado de unos sirvientes inferiores. Pues es natural que a un canallita perdido le ocurran cosas semejantes entre la chusma." ${ }^{3}$

Fijémonos, pues, en las similaridades que hay entre los dos libros; señalemos las semejanzas entre los dos pícaros. Ambos son escribanos, bachilleres latinistas, y aprendices de médico; los dos describen una epidemia diezmadora. Tanto en Gil Blas como en Periquillo Samiento figuran el episodio de los ladrones y el incidente de los mendigos. Tanto Perico como Gil sufren encarcelamiento. E1 viaje de Perico a las Filipinas y su naufragio y estancia en la isla del Mandarín, recuerdan la historieta que Rafael cuenta a Gil de su "cautiverio feliz", en Turquía. Bellacos y cobardes son ambos héroes, e igualmente crueles con sus padres.

El doctor Purgante en Periquillo Sarniento, es una caricatura de los medicuchos ignorantes del tiempo de Lizardi, pero sin duda alguna está calcado del doctor Sangrado, de Gil Blas. Lesage se contenta con meramente esbozar esta figurita con dos o tres garabatazos: "Aquél médico sabio era de exterior grave. Pesaba sus palabras, lo que según él daba mayor nobleza a sus expresiones. Sus razonamientos parecían medidos geométricamente, y sus opiniones asaz singulares." ${ }^{4}$ Lizardi no se limita a indicarnos la pedantería y la charlatanería características de Purgante, sino que nos las hace patentes: "Qué estulticia!, exclamó el doctor - la veracundia es 'muy butena" optime bona cuando la origina crimen de cogitato mas no cuando se comete involunie, pues si en aquel hic et nunc 'esto es en aquel acto', supiera el individuo que hacía mal, absque dubio, 'sin duda' se abstendría de cometerlo. En fin hijo carísimo, etú quieres quedarte en mi servicio y ser mi consodal in perpetuum, "para siempre'?" 5

Ambos autores nos explican el porqué del apodo de su médico. Sangrado mataba a sus pacientes a fuerza de sangrías copiosas y mucho beber de agua caliente, y le dice a Gil: "Sábete que no hay más que sangrar y hacer beber agua caliente. He aquí el secreto para curar todas las enfermedades del mundo." ${ }^{6}$

El doctor Purgante es un poco más original en su método de despachar a sus enfermos al otro mundo; los acaba a fuerza de fuer- 
tes purgas. Es muy posible que Lizardi haya sacado el apelativo de su doctorzuelo de la obra de Lesage. Sangrado, hablando de cierto caso, se expresa de la manera siguiente: "Otros, en mi lugar, recetarían remedios salinos, urinosos y volátiles, que por la mayor parte contienen algo de azufre y mercurio. Pero los purgantes y los sudoríficos son drogas perniciosas, e inventadas por curanderos." 7 Lo que tal vez inspirara a Lizardi a describir a Purgante como "un médico viejo a quien llamaban por mal nombre el doctor Purgante, porque a todos los enfermos decía que facilitaba la curación con un purgante." 8 La cual es una manera no menos eficaz y sí más original de matar enfermos.

Con qué gracia nos describe Lizardi el traje doctoral de Perico: ". . vestido de ceremonia, quiero decir, con mi capa de golilla, la golilla misma y mi peluca encasquetada, porque no tenía traje mejor ni peor; siendo lo más ridículo que mis medias eran blancas, todo el vestido de color y los zapatos abotinados, con lo que parecía más bien alguacil que médico." 9 Traje semejante al que llevaba Gil: "Llevaba yo una capa que me arrastraba, una chupa y unos calzones tan largos que había allí material para cuatro de mi tamaño. En fin, mi figura podía pasar por original y grotesca." 10

Purgante y Sangrado tienen mucho de parecido, pues además de ser un par de curanderos tunantes, ambos son cicateros y miserables y casi matan a sus criados de hambre: "Se vivía muy frugalmente en su casa. Por lo regular no comíamos más que chícharos, habas, manzanas cocidas o un poco de queso. El decía que estos alimentos eran los más convenientes al estómago, por prestarse más bien a la trituración", ${ }^{11}$ nos dice Gil, el portavoz de Lesage. Lizardi, que sabe sacar partido de cada situación, relata con más gracia la frugalidad de Purgante. Este le dice a Perico: “...tendrás 'desde luego, o en primer lugar' in primis el panem nostrum quotidianum 'el pan de cada día; a más de esto', aliunde, lo portable necesario; tertio, la cama sic vel sic 'según se proporcione'; quarto, los tegumentos exteriores heterogéneos de tu materia física; quinto, asegurada la parte de higiene que apetecer puedes, pues aquí se tiene mucho cuidado con la dieta." 12

El episodio de la epidemia sólo tiene de diferente el hecho de que Perico pasa por doctor, habiéndole robado a Purgante sus instrumentos, diploma, libros, ropas, y hasta la pedantería, mientras 
que Gil es un mero ayudante. Aquél describe el nefasto acontecimiento de la manera siguiente: "... acaeció en aquel pueblo, por mal de mis pecados, una peste del diablo, que jamás supe comprender; porque les acontecía a los enfermos una fiebre repentina, acompañada de basca $y$ delirio, y en cuatro o cinco días tronaban. Yo leía a Tissot, a madama Fouquet, Gregorio López, al Bucham, el Vanegas y cuantos compendistas tenía a la mano; pero nada me valía, los enfermos morían a mil aradas. Por fin, y para colmo de mis desgracias, según el sistema del doctor Purgante, di en hacer evacuar a los enfermos el humor pecante, y para esto me valí de los purgantes más feroces, y viendo que con ellos sólo morían los pobres extenuados, quise matarlos con cólicos que llaman 'Misereres', o de una vez envenenados." 13

Gil describe el mismo episodio de la siguiente manera: "Comenzaron unas fiebres malignas en la ciudad y en los suburbios. Todos los médicos de Valladolid ejercieron, y nosotros en particular. No había día que cada uno visitáramos ocho o diez enfermos, lo. que supone mucha agua bebida y mucha sangre derramada. Mas yo no sé cómo era esto; todos se nos morían, sea que nuestro tratamiento fuera propicio a esto, sea que sus enfermedades fueran incurables. Rara vez le hacíamos tres visitas a un mismo enfermo. Después de la segunda o sabíamos que lo acababan de enterrar o lo encontrábamos en agonía." 14

Con la excepción del habla que siempre es culta hasta el punto de la altisonancia en Gil Blas, no parece haber gran diferencia entre las dos obras en cuanto al episodio de los salteadores de caminos. E1 héroe en ambas obras cae en las garras de éstos y se ve forzado a participar en sus crimenes. Lesage convierte el trance en episodio detectivesco; Lizardi se sirve de él para escarmentar a su personaje y sacarle del camino de la perdición y encaminarle hacia la salvación. Gil describe sus ropas y armazón: "Estaba yo armado como ellos de una carabina, dos pistolas, de una espada y una bayoneta y montaba un caballo bastante bueno, que le habían quitado al mismo caballero cuyas ropas llevaba yo." 15 E1 aparejo de Perico no es muy diferente. "Después ensillaron mi caballo y me pusieron dos pistolas en la cintura, una cartuchera y un sable; me acomodaron una mojarra en la bota, y me pusieron una carabina en la mano." 16 
En el primer robo que ayudan a cometer Perico y Gil, ambos demuestran lo cobardes que son. Perico confiesa que "... como la consideración del riesgo que me amenazaba me hacía temblar como un azogado, sin poder disimular el miedo, de modo que mi temor se hizo sensible, porque como mis piernas temblaban tanto, hacían las cadenillas de las espuelas un sonecillo tan perceptible con los estribos que llamó la atención del Agtulucho." 17 Tal confesión recuerda la de Gil, quien se mostró igualmente carente de valor: "No obstante los aplausos que había recibido en el bosque, me sentí sacudido por un fuerte temblor, y luego me sentí todo el cuerpo bañado de un sudor frío, que no me presagiaba nada bueno."'18

Gil continúa su relato del encuentro: "... Yo cerré los ojos y volteé la cabeza al descargar mi carabina, de manera que aquel disparo nunca puede ser cargo de mi conciencia." ${ }^{19}$ Perico, que siempre da la nota ridícula, no queda más bien: "Yo disparé mi escopeta con mala intención, pero sólo se logró el tiro en un caballo." ${ }_{20}$

La novela de Lesage en realidad no es sino una serie de historietas o anécdotas, ensartadas en la hebra de la vida del héroe, Gil. En la de Lizardi no hay nada de aquello, pues es su protagonista mismo el que pasa por una aventura tras otra, sufriendo adversidades y gozando de buena fortuna, con la ecuanimidad peculiar al pícaro. Así pues, es el episodio de los mendigos profesionales, en Gil Blos, un mero relato que hace el teniente de los bandidos en un momento expansivo: "... me enhebré con unos pordioseros que pasaban una vida bastante feliz. Me enseñaron a hacer el ciego, a fingir el estropeado, y a ponerme llagas postizas en las piernas, y qué sé yo. Por la mañana, a la manera de actores que se preparan para una comedia, nos ensayábamos nosotros para representar nuestros papeles. Después cada uno se iba a su puesto. Por la noche nos juntábamos, y nos reíamos de los que se habían compadecido de nosotros durante el día." 21

Lesage no nos describe la vida ni el ambiente de esta gentuza, y el resultado es un boceto inacabado, malogrado. Lizardi traza un cuadro gráfico del hampa mexicana - nos pinta su ruindad y nos descubre su miseria vil y su malicia y socarronería. Lo que es más importante aún, hace entrar al lector en la escena a presenciar el drama: "... erá un cuarto de casa de atoleras por allá por el barrio de Necatitlán, muy indecente, sucio y hediondo. Allí no había sino 
un braserito de barro que llaman anafre, cuatro o seis petates enrollados y arrimados a la pared, un escaño o banco de palo, una estampa de no sé qué santo en una de las paredes con una repisa de tejamanil, dos o tres cajetes con orines, un banquito de zapatero, muchas muletas en un rincón, algunos tompiates y porción de ollitas por otro, una tabla con parches, aceites y ungüentos y otras iguales baratijas... A este tiempo fueron llegando de uno en uno y de dos en dos, hasta ocho o nueve vagabundos, todos rotos, sucios, emparchados y dados al diablo; pero lo que más me admiró es que conforme iban entrando, arrimaban unos sus muletas a un rincón y andaban muy bien con sus dos pies; otros se quitaban los parches que manifestaban y quedaban con su cutis limpio y sano; otros se quitaban unas grandes pobladas barbas y cabelleras canas con las que me habían parecido viejos y quedaban de una edad regular; otros se enderezaban y desencorvaban al entrar, $y$ todos dejaban en la puerta del cuartito sus enfermedades y males, y aparecían los hombres y aun una mujer que entró, muy útiles para tomar el fusil, y ella para moler un almud de maíz en un metate... -pues, amigo - me contestó el roto-, a bien que es usted de confianza y le importa guardar el secreto. Nosotros ni somos cojos, ni ciegos, ni corcovados como parecemos en las calles. Somos unos pobres mendigos que echando relaciones, multiplicando plegarias, llorando desdichas y porfiando y moliendo a todo el mundo, sacamos mendrugo al fin. Comemos, bebemos ( $y$ no agua), jugamos, y algunos mantenemos nuestras 'pichicuaracas' como Anita ... El modo es - proseguía el desastrado-, fingirse ciegos, baldados, cojos, leprosos y desdichados de todos modos; llorar, pedir, rogar, echar relaciones, decir en las calles blasfemias y desatinos, e importunar al que se presente..., dígame cuál es su vocación para habilitarlo de lo necesario. Si quiere ser cojo, le daremos muletas; si baldado o tullido, su arrastradera de cuero; si llagado, parches y trapos llenos de aceites; si anciano decrépito, sus barbas y cabellera; si asimplado, usted sabrá lo que ha menester, y en fin, para todo tendrá los instrumentos precisos, entrando en esto los tompiates, ollas, trapos y bordones o báculos que necesite... También es necesario que sepa usted el orden de pedir según los tiempos del año y días de la semana." 22 
Hay otro episodio de un realismo nauseabundo que aparece en las dos obras. E1 cómico resultado de la estratagema de que se vale Gil para escaparse de la cueva de los bandoleros, tiene un paralelo en Periquillo Sarniento. Gil finge tener un cólico, dando gritos desaforados y retorciéndose endemoniadamente: "En una palabra, desempeñaba mi papel con tanta destreza, que los ladrones, no obstante ser tan astutos, se dejaron engañar y creyeron que en realidad sufría dolores violentísimos. Pero por hacer mi papel tan bien, sufrí una tormenta extraña, pues luego que mis compadecidos compañeros pensaron que sufría, se apresuraron a socorrerme. Uno me traía una botella de aguardiente y me hacía beber la mitad, otro, a pesar mío, me ponía una lavativa de aceite de almendras dulces, otro iba a calentar una servilleta y casi ardiendo me la aplicaba a la boca del estómago." ${ }^{23}$ Lizardi describe su episodio con más malicia. Perico, ya médico acreditado en Tula, va a atender al tendero más rico del pueblo, quien se moría de un cólico. Aquél, prevenido de una jeringa, manda cocer malvas con jabón y miel: "... le hice tomar una buena porción por la boca, a lo que el miserable se resistía y sus deudos, diciéndome que eso no era vomitorio, sino ayuda ... El triste enfermo bebió la asquerosa porción con tanto asco, que con él tuvo para volver la mitad de las entrañas; . . . entonces hice que Andrés llenara la jeringa y le mandé franquear el trasero... - En mi vida - me dijo el enfermo-, - en mi vida me han andado por ahí...-Pues amigo --le respondí--, en su vida se habrá visto más apurado, ni yo en la mía ni en los años que tengo de médico, he visto cólico más renuente." 24

En cuanto a la psicología, mucho hay de parecido entre los dos personajes. Tan oportunista y calavera es el uno como el otro; ambos son cobardes, enamorados y mal correspondidos, comelones, ingenuos y mentecatos; los dos se dejan arrastrar por sus pasiones, pronto les remuerde la conciencia, vierten lágrimas de cocodrilo, hacen votos de enmienda, y vuelta a lo de siempre.

Gil sufre uno de estos ataques de conciencia a la tercera semana de estar de mayordomo entre los actores del Teatro del Príncipe en Madrid: "Cedí al torrente, y por tres semanas me entregué a todo género de placeres; pero debo decir que en medio de ellos sentía remordimientos, procedentes de mi educación, que llenaban de amarguras mis delicias. No triunfó mi perdición sobre estos re- 
mordimientos, al contrario éstos eran mayores cuanto más me entregaba al libertinaje." ${ }^{25}$ Perico, en uno de estos arrebatos pasajeros, se expresa de la manera siguiente: "Yo estaba prostituído; pero sentía una genial repugnancia y hastío en estas cosas. No sé qué tiene la buena educación en la niñez, que en la más desbocada carrera de los vicios, suele servir de un freno poderoso que nos contiene." 26

No hemos mencionado el episodio del encarcelamiento de Perico y Gil, porque en realidad es más la diferencia que la similaridad. Lesage no se detiene a glosar este incidente, no sólo porque nunca conoció la prisión, sino porque aparentemente carecía por completo de conciencia social. Lizardi, que había sufrido prisión, supo describirla casi desde el punto de vista de un penalista, atacando los crímenes y abusos que se cometían a rienda suelta en las prisiones mexicanas. Como se ve, el fin de cada escritor era distinto.

También es cierto que aunque los dos pícaros desempeñan el papel de escribanos, el punto de vista de Lesage es muy diferente al de Lizardi. Aquél quiso censurar la venta de favores y puestos administrativos; éste ahonda más, entra en materia y critica otro aspecto de la sociedad de su tiempo: la estupidez de los administradores que permitían que el escribano tuviera más o menos poder absoluto sobre los reos, debido al analfabetismo de éstos.

Jefferson-Rea Spell expresa la siguiente opinión sobre Lizardi: "But in spite of the extent of his borrowings, Lizardi is not guilty of anything that can fairly be called plagiarism." 27 Sugerir el plagio para luego negarlo nos parece inconsistente. De ninguna manera se podrá calificar de plagio lo que Lizardi hizo, pues le ha quitado a su protagonista el "manteau" francés para cubrirle con el sarape mexicano; le ha despojado de las sandalias hebilladas y las medias de seda, para calzarlo de huaraches al raso; le ha trocado en calzón blanco los pantaloncitos de terciopelo; el chaquetín y la camisa de cambray se las ha reemplazado con la camisa de percal y la chupa. Inspirarse en un modelo no es plagio.

La psicología de Perico, forjada a consecuencia de su ambiente tan distinto al de Gil, ya nada tiene de francés; su filosofía, callejera y de ocasión como la de Gil, eso sí, restulta vivo reflejo de su mexicanismo. E1 lenguaje, matizado de giros indígenas, es de gran 
naturalidad y rebosa de sabor a nuevo mundo. Lizardi, pues, no se contentó con mudarle de ropa a su canallita socarrón y fué más allá de meras manifestaciones exteriores. Así, logró la transformación integra de Perico, dotándole de alma inconfundibleniente mexicana.

Carlos lozano

\section{$N O T A S$}

1 J. J. Fernández de Lizardi, El Periquillo Sarniento, (Ed. Sopena), Barcelona, 1908, p. 6.

2 Ibid., p. 7.

3 Ibid., p. 6.

4 Lesage, Alain-René, Gil Blas de Santillane, Paris, 1935, I, p. 98: "Ce sçavant médecin avait l'extérieur grave. Il pesoit ces discours et donnoit de la noblesse à ses expressions. Ses raisonnemen's paroissoient géométriques, e ses opinions fort singulières."

5 Periquillo Sarniento, p. 160.

6 "Sçache, mon ami, qu'il ne faut que saigner, et faire boire de l'eau chaude. Voilà le secret de guerir toutes les maladies du monde." Gil Blas de Santillane, I, p. 108.

7 Gil Blas, I, p. 98. "D'autres à ma place, ordonneroient sans doute des remèdes salins, urineux, et volatils, et qui pour la plupart participent de soulfre et de mercure. Mais les purgatifs et les sudorifiques sont des drogues pernicieuses et inventées par des charlatans."

8 Periquillo Sarniento, p. 152.

9 Ibid., p. 163.

10 Gil Blas, I, p. 109. "J'avais un manteau qui trainoît à terre, avec un pourpoint et un haut de chausses quatre fois plus long et plus large qu'il ne falloit. Je pouvois passer pour une figure originale et grotesque."

11 Lesage, op. cit., I, pp. 105-6: "On vivoit chez lui très frugalement. Nous ne mangions d'ordinaire que des pois, des féves, des pommes cuites ou du fromage. Il disoit que ces alimens étoient le plus convénables à l'estomac, comme étant les plus propres à la trituration."

12 Fernández de Lizardi, op. cit., p. 160.

13 Fernández de Lizardi, ibid., p. 176. 
14 Lesage, op. cit., pp. 124-125. "Des fiévres malignes commencerent à régner dans la ville et dans les fauxbourgs. Tous les Médecins de Valladolid eurent de la pratique, et nous particulierement. Il ne se passoit point de jour que nous ne vissions chacun huit ou dix malades. Ce qui suppose bien de l'eau bûë et du sang répandu. Mais je ne sçai pas comment cela se faisoit; ils mouroient tous, soit que nous les traitassions d'une maniere propre à cela, soit que leurs maladies fussent incurables. Nous faisions rarement trois visites à un même malade. Dès la seconde, nous apprenions qu'il venoit d'être enterré, ou nous le trouvions à l'agonie."

15 Lesage, op. cit., I, p. 37: "J'etois armé comme eux d'une carabine, de deux pistolets, d'une épée et d'une bayonnette, et je montois un assex bon cheval, qu'on avait pris au mème Gentilhomme dont je portois les habits."

16 Fernández de Lizardi, op. cit, p. 269.

17 Ibid., p. 270.

18 Lesage, op. cit., I, p. 41: "Malgré les applaudissemens que j'avois reçus dans le bois, je me sentis saisí d'un grand tremblement et bientôt il sortit de tout mon corps une sueur froide, qui ne me présageoit rien de bon."

19 Lesage, op. cit., I, p. 42: “.. .je fermai les yeux et tournai la tête en déchargeant ma carabine, et de la maniere que je tirai, je ne dois point avoir ce coup-là sur la conscience,"

20 Fernández de Lizardi, opp. cit., p. 270.

21 Lesage, op. cit., I, p. 28: “... je me fauxfilai avec des gucux, qui menoient une vie assez heureuse. Ils m'apprirent à contrefaire l'aveugle, à paroitre estropié, à mettre sur les jambes des ulcères postiches, 'et coetera'. Le matin, comme des acteurs qui se préparent à joüer une conedie, nous nous disposions à faire nos personnages. Chacun couroìt à son poste; et le soir nous réünissant tous, nous nous rejö̈ssions pendant la nuit au dépens de ceux qui avoient eu pitié de nous pendant le jour."

22 Fernández de Lizardi, op. cit, pp. 204 ff.

23 Lesage, op. cit., I, p. 46: "En un mot, je joüai si bien mon rôle, que les voleurs, tous fins qu'ils étaient, s'y laisserent tromper, et crurent qu'en effet je sentois des trenchées violentes. Mais en faisant si bien mon personnage je fus tourmenté d'une étrange façon; car dès que mes charitables confrères s'imaginerent que je souffroit, les voilà tous qui s'empressent à me sonlager. L'un m'apporte une bouteille d'eau de vie, et m'en fait avaler la moitié, l'attre me donne malgré moi un lavement d'huile d'amandes douces, un autre va chauffeur une serviette et vient me lappliquer toute brûlante sur le ventre."

24 Fernández de Lizardi, op. cit, pp. 166-167. 
25 Lesage, op. cit., I, p. 240: "Je cédai au torrent pendant trois semaines. Je me livrai à toutes sortes des voluptez. Mais je dirai en même tems qu'au milieu des plaisirs, je sentois souvent naître en moi des remords qui venoient de mon éducation, et qui mêloient une amertume à mes delices. La débauche ne triompha point de ces remords; au contraire, ils augmentoient à mesure que je devenois plus débauché."

26 Fernández de Lizardi, op. cit., p. 121.

27 Spell, Jefferson-Rea, Life and Works of José Joaquin Fernóndes de Lizardi, Philadelphia, 1931, p. 91. 